\title{
Research Paper \\ A Model to Develop Ecovillages in Iran, Based on the Qualitative Content Analysis of the Websites of Ecovillages Worldwide: An Old Model in New Era
}

\author{
*Shahrzad Barani ${ }^{1}$, Amir Hossein Alibeygi ${ }^{2}$, Abdolhamid Papzan ${ }^{2}$
}

1. PhD Candidate, Department of Extension and Rural Development, Faculty of Agriculture, Campus of Agriculture and Natural Resources, Razi University, Kermanshah, Iran. 2. Associate Professor, Department of Extension and Rural Development, Faculty of Agriculture, Campus of Agriculture and Natural Resources, Razi University, Kermanshah, Iran.

Received: 05 Jun. 2016

Accepted: 27 Nov. 2016

Key words:

Content analysis,

Ecovillage, Model,

Sustainable devel-

opment, Iran
Chtation: Barani, Sh., Alibeygi, A. H., \& Papzan, A. (2017). [A Model to Develop Ecovillages in Iran, Based on the Qualitative Content Analysis of the Websites of Ecovillages Worldwide: An Old Model in New Era (Persian)]. Journal of Rural Research, 8(1), 6-21. http://dx.doi.org/10.21859/jjr-08011

dol: : http://dx.doi.org/10.21859/jjr-08011

\section{Extended Abstract}

\section{Introduction}

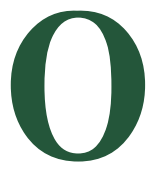

ne of the recent achievements of human to reduce the ecological footprint is creation, expansion, and rehabilitation of a large number of small and sustainable habitats called "ecovillages" as the beating hearts of sustainable nature systems worldwide. These habitats are the most practical and most administrative models for planning and organizing human settlements in the $21^{\text {st }}$ century. In this context, many developed and developing countries pioneered and scored extraordinary measures. It is highly important and significant to identify and compare the patterns of development of the societies in such countries that rely on their knowledge and experience in this direction, and makes the way shorter to achieve the goal for other countries. For Iran also, to benefit from an efficient model for sustainable development is the concern of most governments. On the other hand, the research on ecovillages is a relatively new phenomenon and its concept is discussed in a small number of research projects. The research literature clearly indicated the need to the content analysis based on the experiences and characteristics to reveal unique patterns of such communities.

\section{* Corresponding Author:}

Shahrzad Barani, PhD Candidate

Address: Department of Extension and Rural Development, Faculty of Agriculture, Campus of Agriculture and Natural Resources, Razi University, Imam Khomeini Highway, Kermanshah, Iran.

Tel: +98 (937) 8579818

E-mail: barani705@yahoo.com 


\section{Methodology}

The current study used the qualitative research approach and qualitative content analysis from the websites of ecovillages worldwide, with conventional inductive approach, to design a model for ecovillages development in Iran . For this purpose, from a random sample of 50 ecovillages in the developing and developed countries, 25 cases (11 developing and 14 developed countries) that represented the main important features and characteristics of their community on their websites, were selected and analyzed (from 2014 to 2015). To achieve the quality of research that is equivalent to the validity and reliability of qualitative research, provide a clear and transparent manner of the study process, and repeat coding by other researchers in 10 percent text and compare the results of coding was done.

\section{Results}

Twenty-four indicators derived from the qualitative content analysis were classified into 2 strategies (Behavior-based and technology-oriented), and set based on a continuum from the most advanced technology-based strategy to the most significant indicators of behavioralbased strategy. The movement pattern and development of ecovillages in the developing countries based on strategies/indicators, and year of establishment were designed, analyzed, and compared with the trend in the developed countries. Germany has the highest focus on technologybased strategy and lowest focus on behavior-based strategy to develop its ecovillages. Australia relies on both types of strategies to develop ecovillages. In Japan and the United Kingdom with respect to the progress of technology and their industrial background, the main emphasis is on technology-based strategy. India, among the developing countries, the third position in world in the field of technology, uses behavioral approaches and sustainability education to develop ecovillages. In South Africa, the process has faced little deviation and technology-based strategy on behaviorbased strategy leads to sustainable development. According to the recent data from the above comparison, a model was proposed to develop ecovillages in Iran.

\section{Discussion}

According to the obtained results, as the first step, Iran should employ behavioral-based strategies to create sustainable models for rural areas as base communities. This proposed model for Iran has features of local and regional flexibility, and also the ability to be generalized to most areas of Iran, because emphasizing on capitals and technologies is compatible with the site in relation to social patterns, behavior, and the culture of indigenous. For
Iran, prioritized planning to develop ecovillages should be considered based on shorter routes such as teaching sustainable behaviors, strengthening social capital, producing organic products, and the use of local materials in construction. Whereas, according to the model, the path to the development of the country through technology-based strategies such as renewable energy, permaculture design, and sustainable economy is more time-consuming; thus, their enhancement is not a priority, but they can be taken in parallel with the promotion of behavioral-based strategies.

\section{Conclusion}

Extensive and deep research in rural areas to identify, collect, and analyze experiences and useful local knowledge for sustainable development of habitats, development, reconstruction, and modernization of rural settlements in accordance with local climatic conditions, diversification of rural economic activities, evaluation of regional potentials, search, matching, and localization of suitable renewable energy technologies, and governmental supports and training, including subsidies, long-term loans, introduction of successful rural samples and establishment of research, extension and education centers to further strengthen and promote organic production and consumption of healthy foods were suggested.

\section{Acknowledgments}

This research was extracted from the MA thesis of the first author, in the Department of Extension and Rural Development, Faculty of Agriculture, Campus of Agriculture and Natural Resources, Razi University, Kermanshah, Iran.

\section{Conflict of Interest}

The authors declared no conflicts of interest. 


\title{
التوى ييشنهادى توسعهزيستبوم هاى يايدار در ايران،مبتنىبر تحليل محتواى كيفى وبنسايتهاي زيستبوم هاى يايدار جهان: التَّى ديرين در عصر نوين
}

\author{
"شهرزاد بارانى'، اميرحسين علىبيكى'، عبدالحميد بابزن' \\ 1- دانشجوى دكترى، كروه ترويج و توسعه روستايى، دانشكده كشاورزى، يرديس كشاورزى و منابع طبيعى، دانشُكاه رازي، كرمائشاه، ايران.

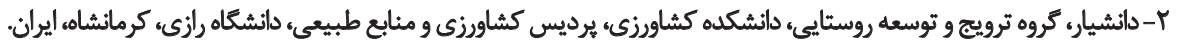

\begin{abstract}
באS1

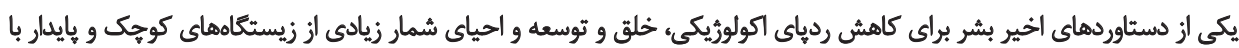

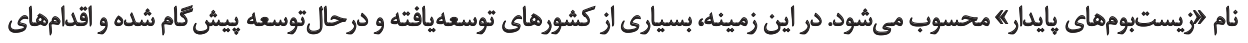

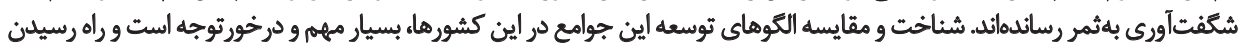

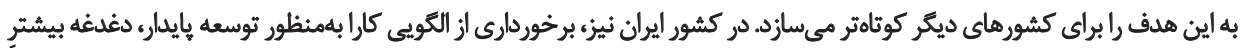

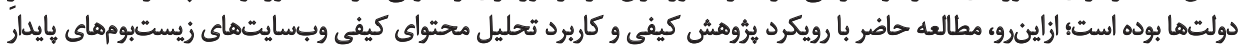

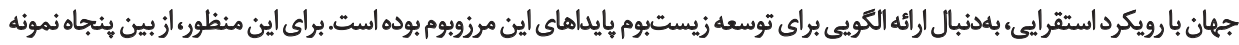

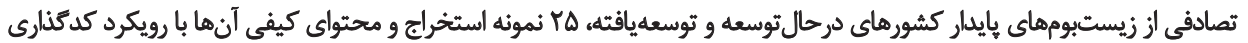

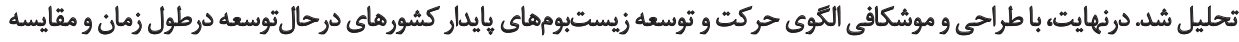

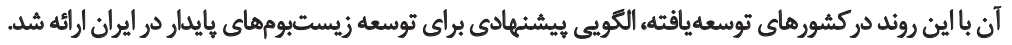

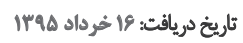

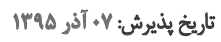

:Lojlg

تحليل محتواء زيستبوم

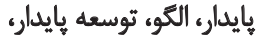
ايران

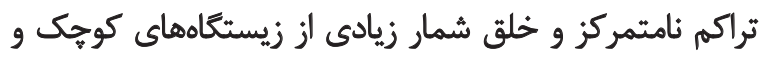

مقدمه

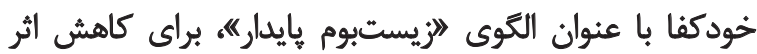

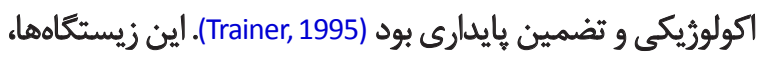

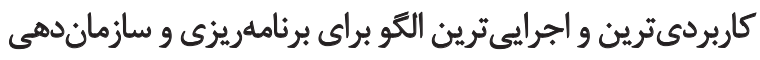

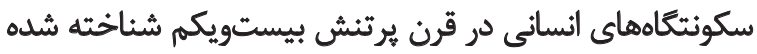

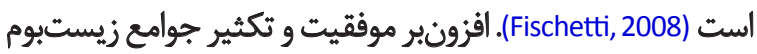

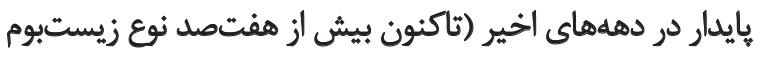

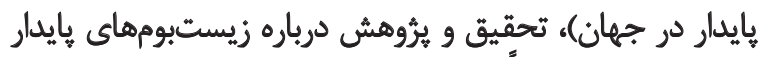

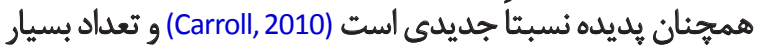

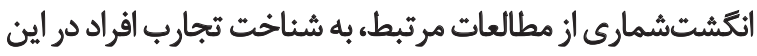

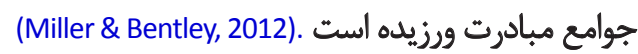

اين در حالى است كه زيستبومهاى هايدار بالغ با استناد به

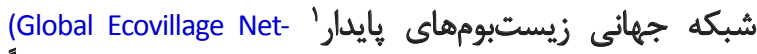

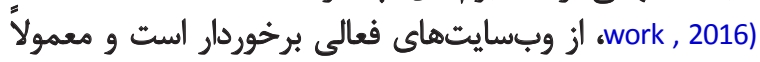

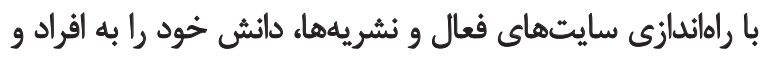
جوامع بزركتر منتقل مي كند (Loezer, 2011)، بنابراين، تحليل

1. Global Ecovillage Network (GEN)

انسان در مسير تمدن خود و بلمددد بيشرفت فناورى آن خهنان

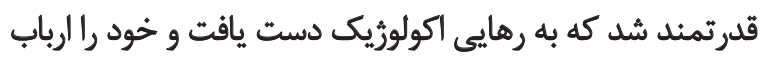

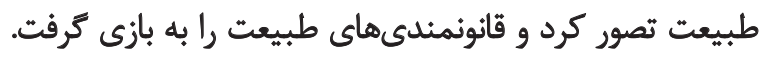

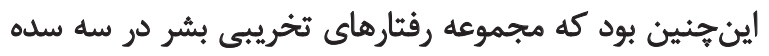

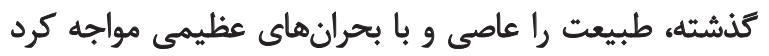
(Zamchevska, 2013)

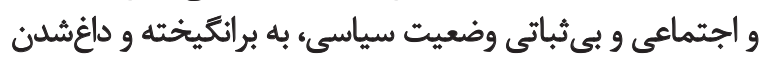

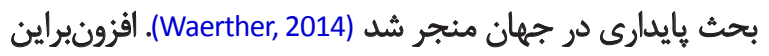

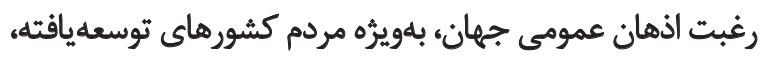

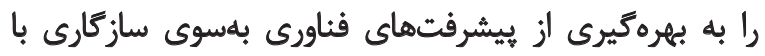

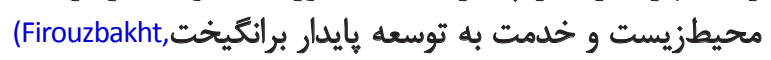

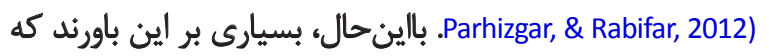

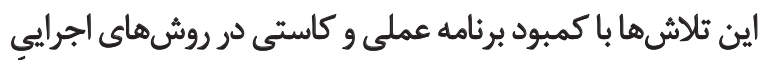

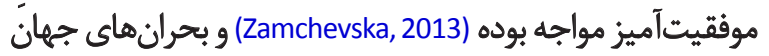
وخيمتر شده است (Carroll, 2010). يكى از راههاى بيشنهادى جوامع جهانى در اين زمينه، 
بهدرستى تحليل شود. هريك از اين جوامع از رهيافت فردى مئ

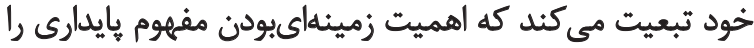

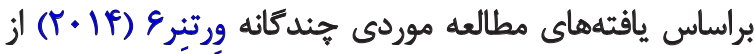

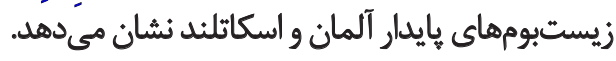

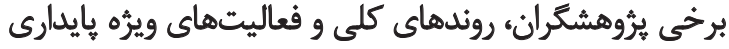

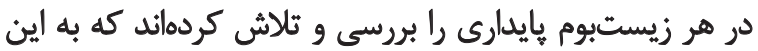

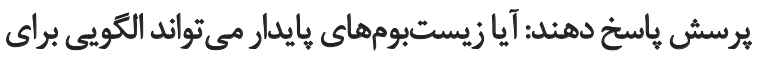

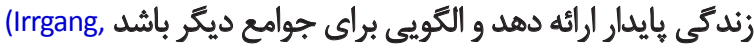
دإئ 2005; Fischetti, 2008; Veteto \& Lockyer, 2008)

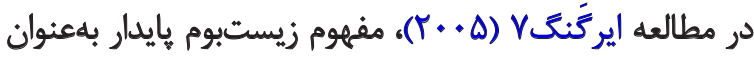

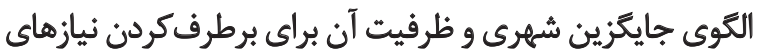

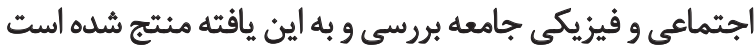

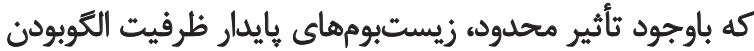

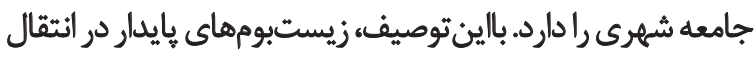

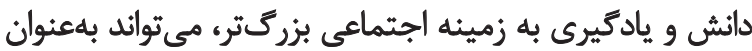

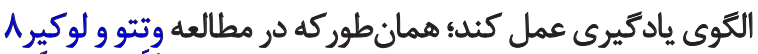

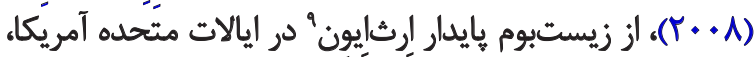
به اين منظور نام برده شده است.

برخي مطالعات بهن نحوه توسعه جوامع زيستبوم يايدار وتحولها

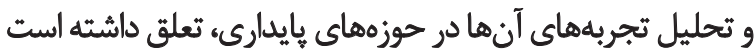

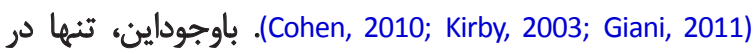

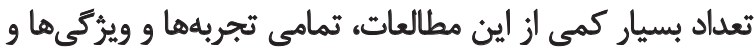

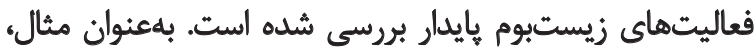

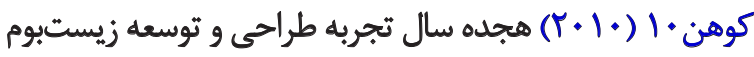

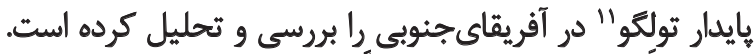

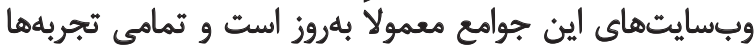

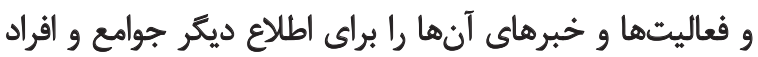

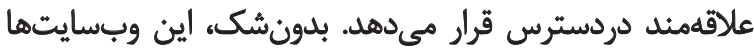

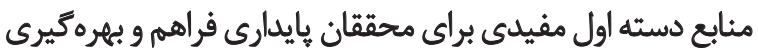
از اين منابع را در قالب تحليل محتوا امكانيذير محفي كنيد.

در برخى ديگر از مطالعات بإيدارى، از تحليل محتواى

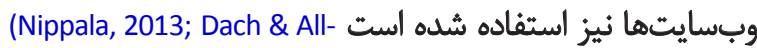
mendinger, 2014).

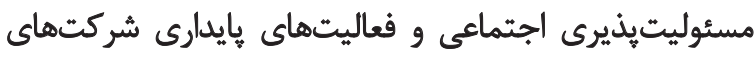

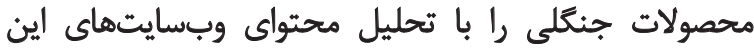
شركتها بررسى كرده است. بنابراين، كاربرد تحليل محتيل وحتواي اين

6. Waertner

7. Irrgang

8. Veteto \& Lockyer

9. Earthaven

10. Cohen

11. Tholego

12. Nippala
محتواي اين سايتها مى توائد اطلاعات ارزشمندى براى محققان

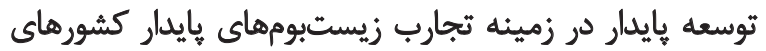

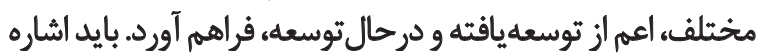

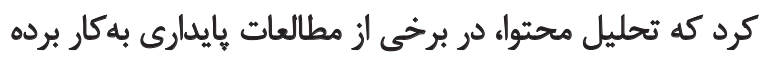

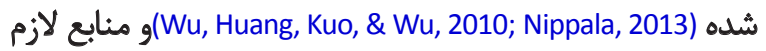

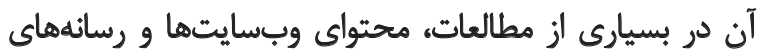
اجتماعى بوده است (Wu et al., 2010; Nippala, 2013). باوجوداين،

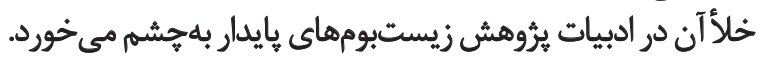
ايران بهعنوان يكى از كشورهاى درحالتوسعه، همواره بهدنبال

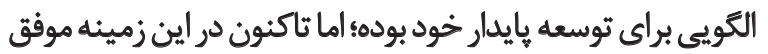

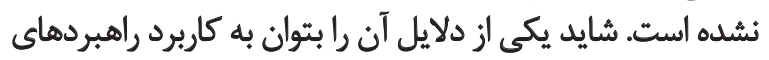

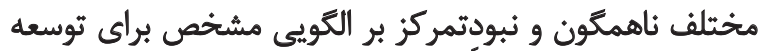

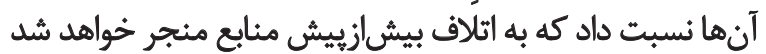

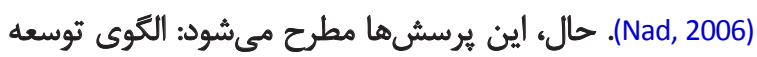

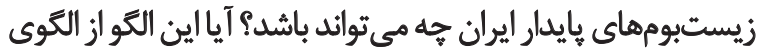

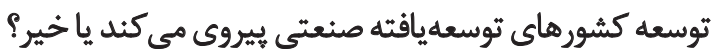

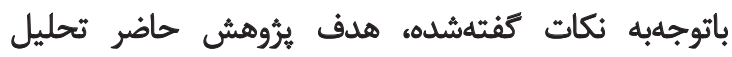

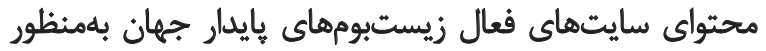

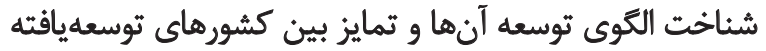

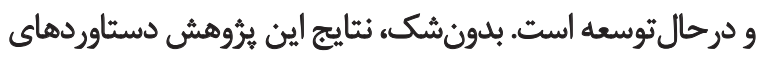

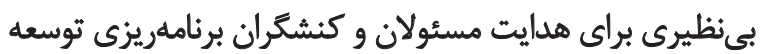
روستايي يايدار در ايران خواهد داشت مسئ.

\section{مرورى بر ادبيات موضوع}

برُوهش در زمينه زيستبومهاى بايدار، بديده نسبتاً جديدى

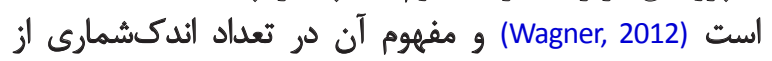

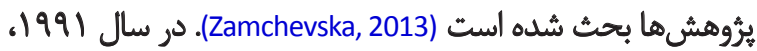

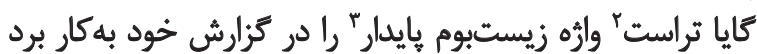
(Zamchevska, 2013; Lin, 2007)

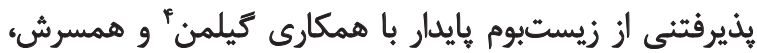

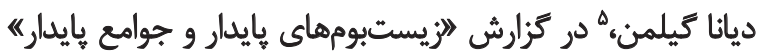

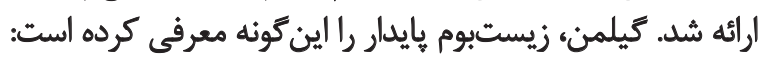

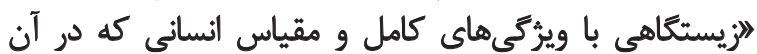

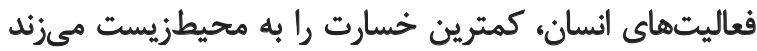

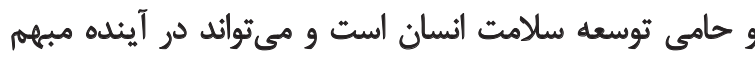

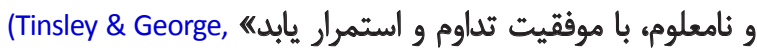

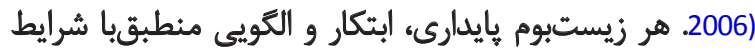

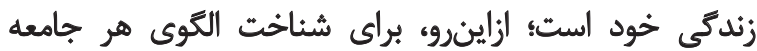

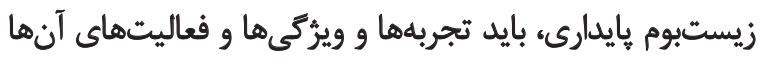

2. Gaia Trust

3. Eco village

4. Gilman

5. Diana Gilman 


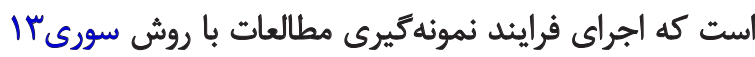

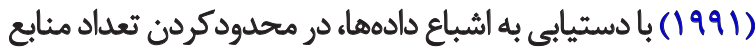

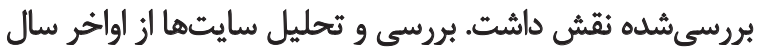

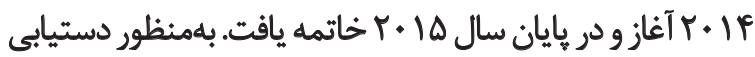

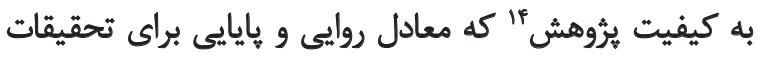

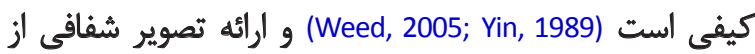

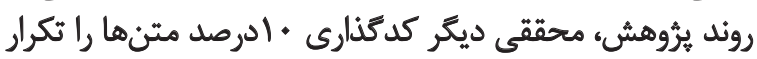

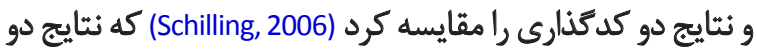
كدگذارى تا حد زيادى با يكديكًر منطبق بود كرد

يافتهها

در جدول شماره ا، وبسايتهاى زيستبومهاي هايدار

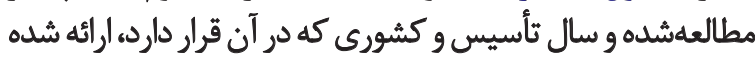

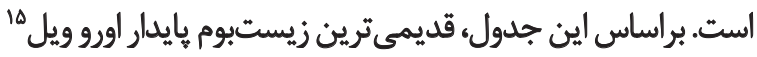

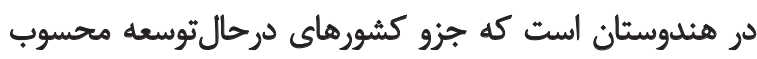

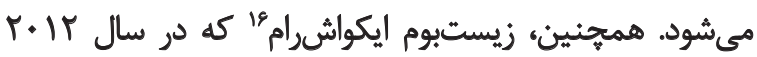

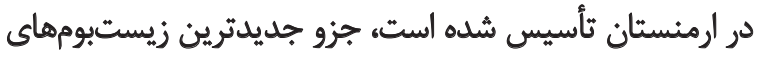

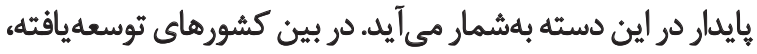

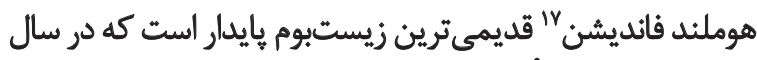

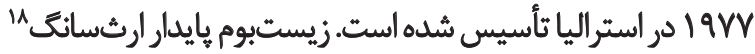

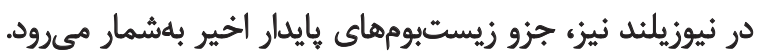

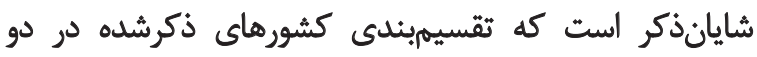

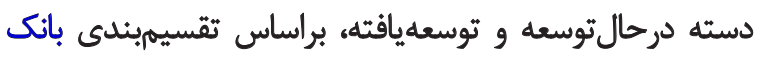

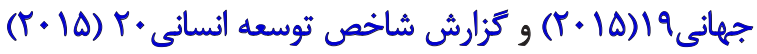

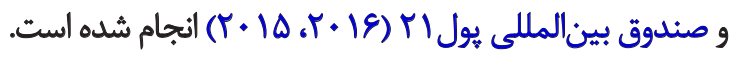
در جدول شماره r، مفاهيم اصلى استخراجشده از تحليل

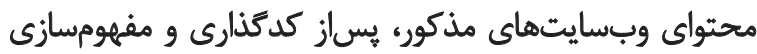

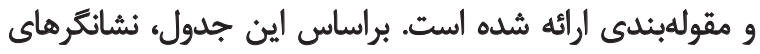

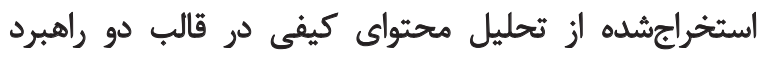

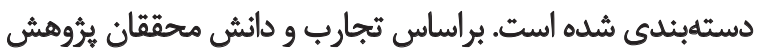

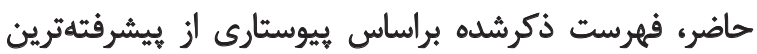

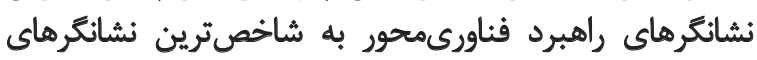

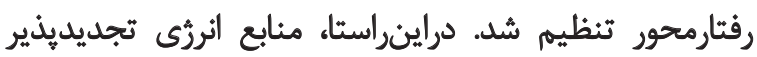

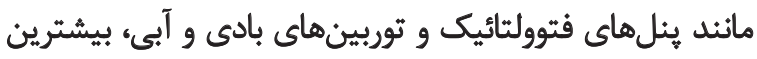

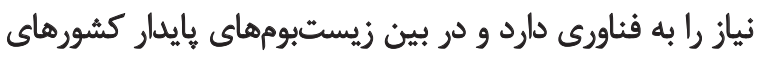

\section{Suri}

14. Research quality

15. Auroville

16. Ecoashram

17. Homeland Foundation

18. Earth Song

19. World Bank

20. Human Development Index (HDI)

21. International Monetary Fund (IMF)
وبسايتها امرى محقق و مستند است. درنهايت، بايد بيان كرد

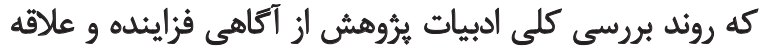

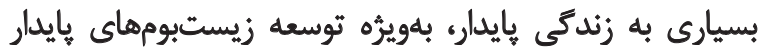

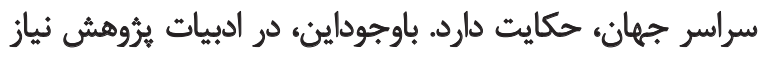

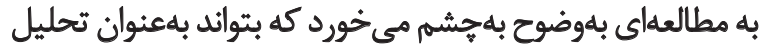

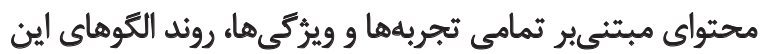
جوامع بىنظير را آشكار كند.

\section{روش شناسى تحقيق}

در اين مطالعه براى تحليل و بررسى منابع، از روش تحليل

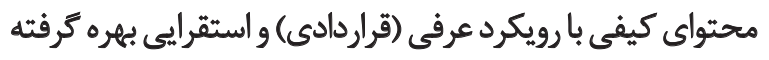

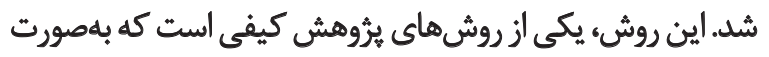

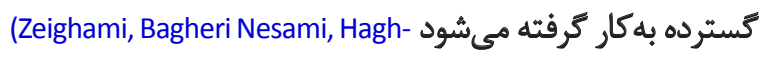

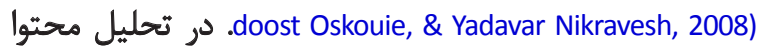

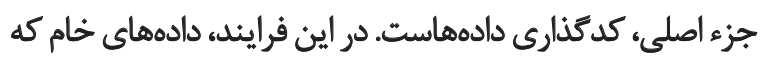

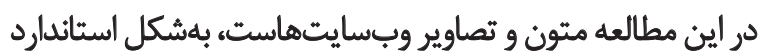

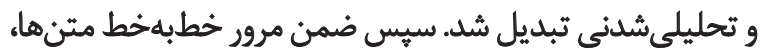

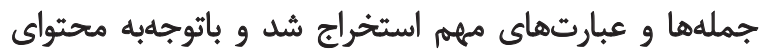

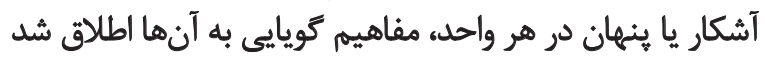

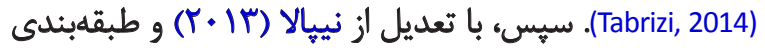

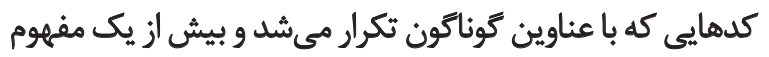

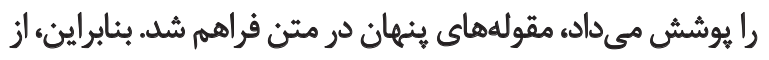

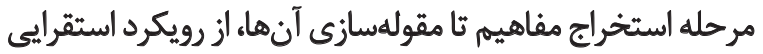

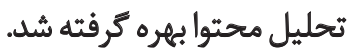
تحليل محتواى يُروهش حاضر، در جهار مرحله سازماندهي شد: ا. نقشه كلى زيستبومهاى بإيدار جهان براساس شبكه جهاني

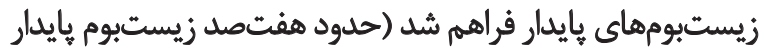

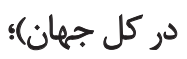

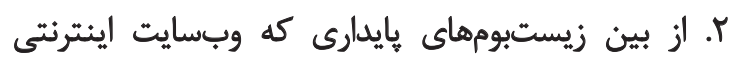

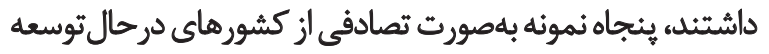

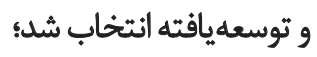

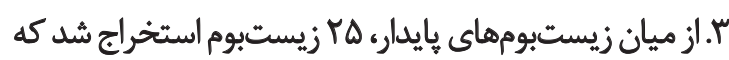

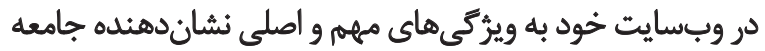

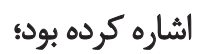
سيس، تصاوير و متون زبان اصلى، به زبان فارسى بركردانده و سيس، محتواى كيفى تحليل شد.

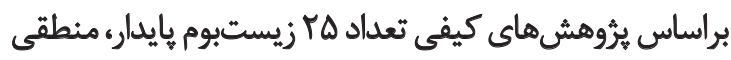

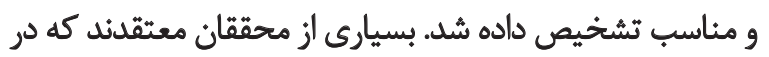

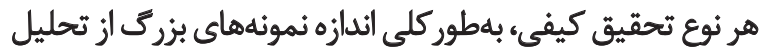

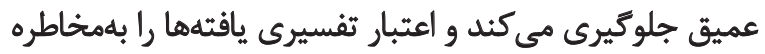

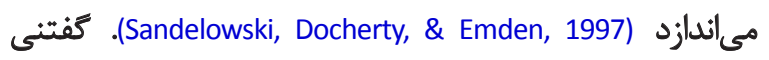


جدول ا. زيستبومهاى بايدار و ويرّكى هاى آنها (مئبع: يافتههاى تحقيق، هوب1)

وببسايت مطالعهشيده

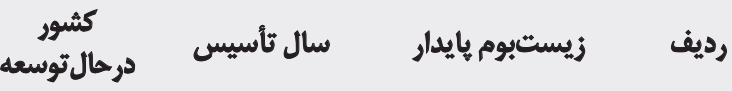

www.auroville.org

http://gen.ecovillage.org

www.ecovillageroad.eu

198 A A $\quad$ A $\quad$ A

www.rucore.org.za

http://gen.ecovillage.org

www.ecovillageroad.eu

199. $\quad$ Tlholego

r

www.sustainabilityinstitute.net

hpp://lynedochecovillage.wordpress.com

http://gen.ecovillage.org

1991

Lynedoch

$r$

www.ecovillageroad.eu

www.volunteeringecotrulypark.blogspote.com

www.volunteer.ecotrulypark.org

http://gen.ecovillage.org

يرو 1990 Eco Truly Park i

www.ecovillage.org.in

http://gen.ecovillage.org

www.ecovillageroad.eu

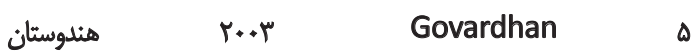

www.webarchiv.nationalarchives.gor.uk

https://www.stichtingveldwerk.nl http://gen.ecovillae.org

ن ب... Hamrogaun \&

www.punpunthailand.org

http://gen.ecovillage.org

www.ecovillageroad.eu

www.eco-rus.info

http://gen.ecovillage.org

www.ecovillageroad.eu

روسيه $\quad$ r.QD Big Stone

$\wedge$

www.sereneecovillage.com

http://gen.ecovillage.org

www.ecovillageroad.eu

r++q $\quad$ Serene

http://www.newoasisforlife.org/2ndhome/Welcome.

html

www.sites.ecovillage.org

Y..9 New Oasis for Life $\quad 1$.

www.globalecovillages.org

www.ecoashram.com

http://gen.ecovillage.org

www.ecovillageroad.eu

www.homeland-foundation.org

http://gen.ecovillage.org

www.ecovillageroad.eu

ثايلئن $\quad$ P..f $\quad$ Pun Pun

www.siriuscommunity.org

http://gen.ecovillage.org

إيالات مثنهله

$19 \vee 4$

Sirius

ir

www.findhorn.org

http://gen.ecovillage.org

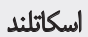

14.

Findhorn

if 
وبسايت مطالعهُشده

www.crystalwaters.org.an

http://gen.ecovillage.org

www.ecovillageroad.eu

www.torri-superiore.org

http://gen.ecovillage.org

www.ecovillageroad.eu

www.ecovillageithaca.org

http://gen.ecovillage.org

www.ecovillageroad.eu

www.earthaven.org

http://gen.ecovillage.org

www.ecovillageroad.eu

www.forum-vauban.de

http://gen.ecovillage.org

www.ecovillageroad.eu

www.ceciliamacaulay.com.au

www.permaculturess.com

http://gen.ecovillage.org

www.bioregional.com

https://en.wikipedia.org

http://gen.ecovillage.org

www.ecovillageroad.eu

www.kibbutzlotan.com

http://gen.ecovillage.org

www.aldingaartsecovillage.com.au

http://gen.ecovillage.org

www.crossroads.org.au

http://gen.ecovillage.org

www.earthsong.org.nz

http://gen.ecovillage.org

www.ecovillageroad.eu

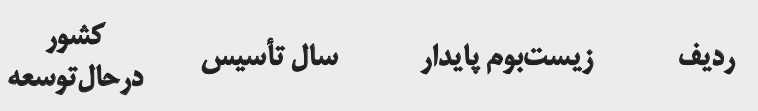

استراليا $\quad$ Crystal Waters $\quad$ 19

يتئيا

149 Torri Superiore

18

199. Ithaca IV

1997 إيالات متحده

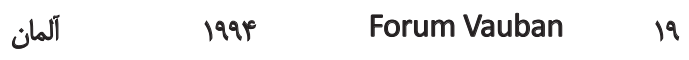

r... $\quad$ Fuji Eco Park r.

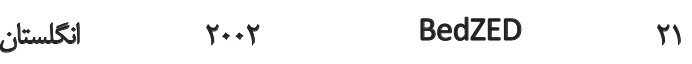

r r..F Kibbutz Lotan

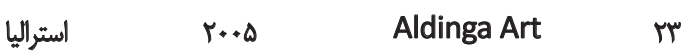

\begin{tabular}{|c|c|}
\hline السترأليا & $r . . r$ \\
\hline
\end{tabular}

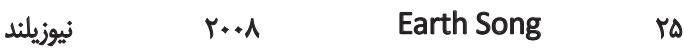

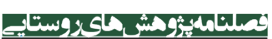

نشانكر ها در راهبرد رفتارمحور در كشورهاي درحالثتوسعه است.

محققان اين يثرهش، بلمنظور كشف و بررسى الكوهاى

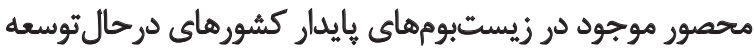

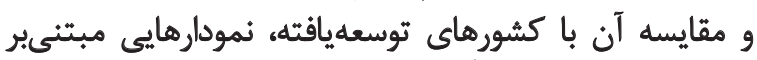

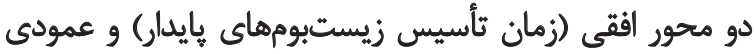

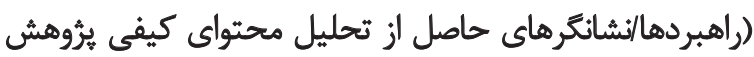

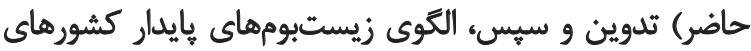

توسعهيافته، با سيزده زيستبوم ثايدار رواج بيشترى دارد. اين در

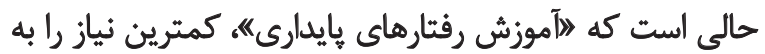

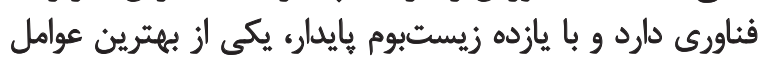

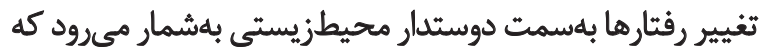

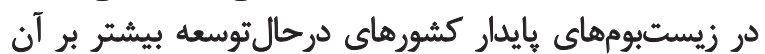

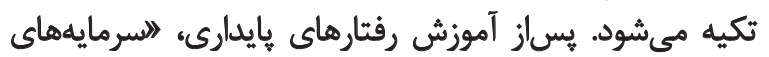

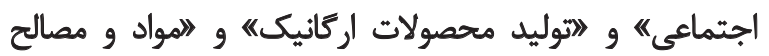

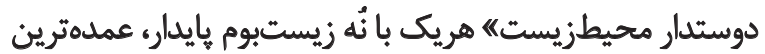


جدول r. راهبردها و نشانكر هاى استخراجشده (منبع: يافتههاي تحقيق، هوبr)

\begin{tabular}{|c|c|c|c|c|}
\hline مثراوانى & زيستبومهاي بايدار حمايت كثنده از مقوله در & فراوانى & 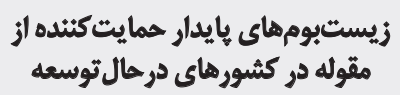 & زيرمقوله/نشائكر \\
\hline
\end{tabular}

Homeland Foundation, Sirrius, Findhorn,

Crystal Waters, Torri

Superiore, Ithaca, Earthaven, Forum

ir Vauban, Fuji Eco Park, BedZED, Aldinga

Art, Earth Song, Crossroads Medieval

Village
Auroville, Tlholego,

Lynedoch, Govardhan,

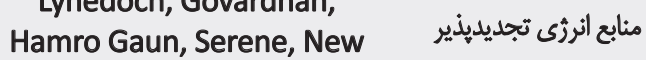

Oasis for Life

Sirius, Forum Vauban, BedZED
$-$
-

Sirius, Findhorn, Crystal Waters, Ithaca,

I) Earthaven, Forum Vauban, Fuji Eco Park,
طراحى خورشيدى Auroville, Govardhan, Hamro Gaun, New Oasis for Life غيرفال
BedZED, Kibbutz Lotan, Earth Song,
Crossroads Medieval Village
BedZED, Kibbutz Lotan, Earth Song
Crossroads Medieval Village
Forum Vauban, Crossroads Medieval Village

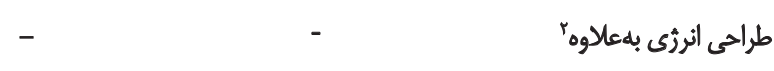
r Tlholego, Lynedoch $\quad$ كاربرد وسايل ائرئى كارآمد أند

Sirius, Findhorn, Crystal Waters, Ithaca, Forum Vauban, Fuji Eco Park, BedZED

Findhorn, Crystal Waters, Torri

1 Superiore, Earthaven, Forum Vauban, Fuji Eco Park, Earth Song, Crossroads Medieval Village

Findhorn, Crystal Waters, Torri 1. Superiore, Ithaca, Earthaven, Forum

Auroville, Tholego, Song, Crossroads Medieval Village

Auroville, Tholego, Lynedoch, Govardhan, Hamro Gaun, Ecoashram

\section{بازيافت و تصفيه} فاضلاب هحلى تاني
Sirius, Findhorn, Crystal Waters, Torri Superiore, Ithaca, Earthaven, Forum 1. Vauban, Fuji Eco Park, Earth Song, Crossroads Medieval Village

Homeland Foundation, Sirius, Findhorn, Crystal Waters, Torri

ir Superiore, Ithaca, Earthaven, Forum Vauban, Fuji Eco Park, Kibbutz Lotan, Aldinga Art, Earth Song
Auroville, Tlholego, Pun Pun, for Life, Ecoashram
V Big Stone, Serene, New Oasis

Auroville, Tlholego,

Lynedoch, Govardhan, بازيافت و تفكيك زبالهها

Hamro Gaun, Serene

جمع آورى آب باران Serene 


\begin{tabular}{|c|c|c|c|c|}
\hline مثراوانى & زيستبومهاى بايدار حمايت كثنده از مقوله در & مُراوانى & زيستبومهاى هايدار حمايت كنينده از & زيرمقوله/:شانكر \\
\hline ir & $\begin{array}{l}\text { Homeland Foundation, Sirius, Findhorn, } \\
\text { Crystal Waters, Torri } \\
\text { Superiore, Ithaca, Forum Vauban, Fuji } \\
\text { Eco Park, Kibbutz Lotan, Aldinga Art, } \\
\text { Earth Song, Crossroads Medieval Village }\end{array}$ & $\checkmark$ & $\begin{array}{l}\text { Auroville, Thholego, } \\
\text { Lynedoch, Govardhan, } \\
\text { Eco Truly Park, Pun Pun, } \\
\text { Ecoashram }\end{array}$ & اقتصاد يايدار هحلى \\
\hline ir & $\begin{array}{l}\text { Sirius, Findhorn, Crystal Waters, Torri } \\
\text { Superiore, Ithaca, Earthaven, Forum } \\
\text { Vauban, Fuji Eco Park, Kibbutz Lotan, } \\
\text { Aldinga Art, Earth Song, Crossroads } \\
\text { Medieval Village, BedZED }\end{array}$ & $\checkmark$ & $\begin{array}{l}\text { Auroville, Tlholego, } \\
\text { Lynedoch, Govardhan, } \\
\text { Eco Truly Park, Serene, } \\
\text { Ecoashram }\end{array}$ & طراحي اقليمى \\
\hline \multicolumn{5}{|c|}{ رفتارمحور (مقوله/راهبرد) } \\
\hline 1. & $\begin{array}{l}\text { Findhorn, Torri Superiore, Ithaca, } \\
\text { Earthaven, Forum Vauban, Fuji Eco } \\
\text { Park, BedZED, Aldinga Art, Earth Song, } \\
\text { Crossroads Medieval Village }\end{array}$ & r & Auroville, Govardhan & 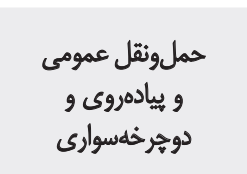 \\
\hline 1. & $\begin{array}{l}\text { Sirius, Findhorn, Crystal Waters, Torri } \\
\text { Superiore, Ithaca, Earthaven, Forum } \\
\text { Vauban, Kibbutz Lotan, Aldinga Art, } \\
\text { Earth Song }\end{array}$ & 9 & $\begin{array}{l}\text { Auroville, Tlholego, } \\
\text { Lynedoch, Govardhan, } \\
\text { Eco Truly Park, Pun Pun, } \\
\text { Serene, New Oasis for Life, } \\
\text { Ecoashram }\end{array}$ & موادو مصيطزالح دوستّار \\
\hline if & $\begin{array}{c}\text { Homeland Foundation, Sirius, Findhorn, } \\
\text { Crystal Waters, Torri } \\
\text { Superiore, Ithaca, Earthaven, Forum } \\
\text { Vauban, Fuji Eco Park, BedZED, Kibbutz } \\
\text { Lotan, Aldinga Art, Crossroads Medieval } \\
\text { Village, Earth Song }\end{array}$ & $\wedge$ & $\begin{array}{l}\text { Auroville, Thholego, } \\
\text { Lynedoch, Eco Truly Park, } \\
\text { Govardhan, Hamro Gaun, } \\
\text { Pun Pun, New Oasis for Life }\end{array}$ & خودكفايي در توليلا منابع \\
\hline$\wedge$ & $\begin{array}{c}\text { Homeland Foundation, Sirius, Torri } \\
\text { Superiore, Ithaca, Earthaven, Fuji Eco } \\
\text { Park, Aldinga Art, Crossroads Medieval } \\
\text { Village }\end{array}$ & $\checkmark$ & $\begin{array}{c}\text { Auroville, Thholego, } \\
\text { Lynedoch, Eco Truly Park, } \\
\text { Govardhan, Big Stone, New } \\
\text { Oasis for Life }\end{array}$ & حفظ اكونيستمهائ \\
\hline$\checkmark$ & $\begin{array}{l}\text { Homeland Foundation, Sirius, Crystal } \\
\text { Waters, Torri } \\
\text { Superiore, Earthaven, Aldinga Art, } \\
\text { Crossroads Medieval Village }\end{array}$ & r & Auroville, Serene & 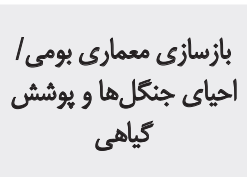 \\
\hline 1. & $\begin{array}{l}\text { Homeland Foundation, Sirius, Findhorn, } \\
\text { Crystal Waters, Torri } \\
\text { Superiore, Ithaca, Earthaven, Fuji Eco } \\
\text { Park, Kibbutz Lotan, Aldinga Art }\end{array}$ & 9 & $\begin{array}{c}\text { Auroville, Tlholego, } \\
\text { Lynedoch, Eco Truly Park, } \\
\text { Govardhan, Hamro Gaun, } \\
\text { Pun Pun, Serene, New Oasis } \\
\text { for Life }\end{array}$ & توليد محصولات \\
\hline 1 & Earth Song & $r$ & $\begin{array}{l}\text { Auroville, Hamro Gaun, New } \\
\text { Oasis for Life }\end{array}$ & روش غالى درمانى سنتى وحلى و \\
\hline$\varepsilon$ & $\begin{array}{l}\text { Sirius, Findhorn, Crystal Waters, Ithaca, } \\
\text { Earthaven, Crossroads Medieval Village }\end{array}$ & $\Delta$ & $\begin{array}{l}\text { Auroville, Tlholego, } \\
\text { Govardhan, Hamro Gaun, } \\
\text { New Oasis for Life }\end{array}$ & 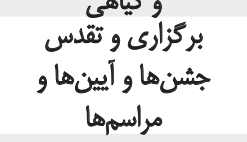 \\
\hline 1. & $\begin{array}{l}\text { Homeland Foundation, Sirius, Findhorn, } \\
\text { Crystal Waters, Torri } \\
\text { Superiore, Ithaca, Earthaven, BedZED, } \\
\text { Crossroads Medieval Village, Earth Song }\end{array}$ & 8 & $\begin{array}{l}\text { Tlholego, Govardhan, Big } \\
\text { Stone, Serene, New Oasis for } \\
\text { Life, Ecoashram }\end{array}$ & هماهنكى فضا با طييتت \\
\hline
\end{tabular}




\begin{tabular}{|c|c|c|c|c|}
\hline فئاوانى & زيستبومهاي بايدار حمايت كثنده از مقوله در & فراوانى & 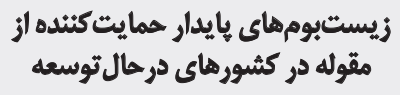 & زيرمقوله/ثشانكر \\
\hline ir & $\begin{array}{c}\text { Homeland Foundation, Sirius, Findhorn, } \\
\text { Crystal Waters, Torri } \\
\text { Superiore, Ithaca, Earthaven, Forum } \\
\text { Vauban, Fuji Eco Park, BedZED, Kibbutz } \\
\text { Lotan, Aldinga Art, Crossroads Medieval } \\
\text { Village }\end{array}$ & 9 & $\begin{array}{l}\text { Auroville, Tlholego, } \\
\text { Lynedoch, Eco Truly Park, } \\
\text { Govardhan, Hamro Gaun, } \\
\text { Pun Pun, Big Stone, New } \\
\text { Oasis for Life, Ecoashram }\end{array}$ & سرمايه اجتماعى \\
\hline r & Crossroads Medieval Village, Earth Song & r & $\begin{array}{l}\text { Auroville, Eco Truly Park, } \\
\text { Govardhan, Ecoashram }\end{array}$ & سلامت روحى و جسمى \\
\hline$\wedge$ & $\begin{array}{c}\text { Homeland Foundation, Sirius, Findhorn, } \\
\text { Torri Superiore, Ithaca, Earthaven, } \\
\text { BedZED, Aldinga Art }\end{array}$ & 8 & $\begin{array}{l}\text { Auroville, Lynedoch, Eco } \\
\text { Truly Park, Govardhan, New } \\
\text { Oasis for Life, Ecoashram }\end{array}$ & 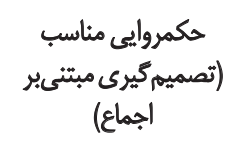 \\
\hline 9 & $\begin{array}{l}\text { Homeland Foundation, Sirius, Findhorn, } \\
\text { Torri Superiore, Ithaca, Forum Vauban, } \\
\text { Fuji Eco Park, Kibbutz Lotan, Crossroads } \\
\text { Medieval Village }\end{array}$ & 11 & $\begin{array}{c}\text { Auroville, Tlholego, } \\
\text { Lynedoch, Eco Truy Park, } \\
\text { Govardhan, Hamro Gaun, } \\
\text { Pun Pun, Big Stone, } \\
\text { Serene, New Oasis for Life, } \\
\text { Ecoashram }\end{array}$ & آموزش رفتارهاى يايدار \\
\hline
\end{tabular}

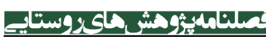

1. Combined Heat and Power

توسعلياقته در توسعه زيستبوم خايدار خود، بيشترين تمركز رابر

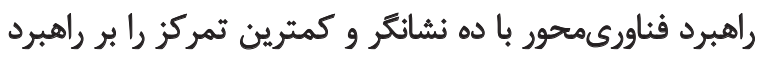

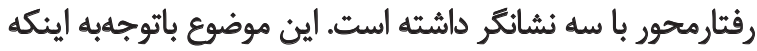

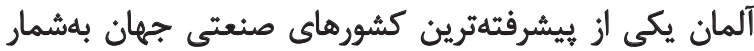

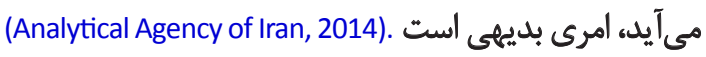

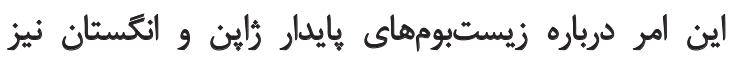

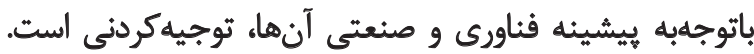

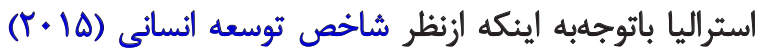

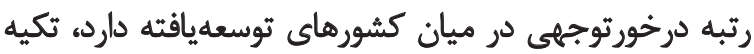

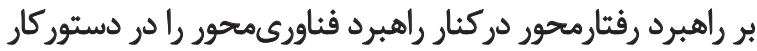
توسعه زيستبومهاى بايدار خود قرار داده است. در تصوير شماره راره

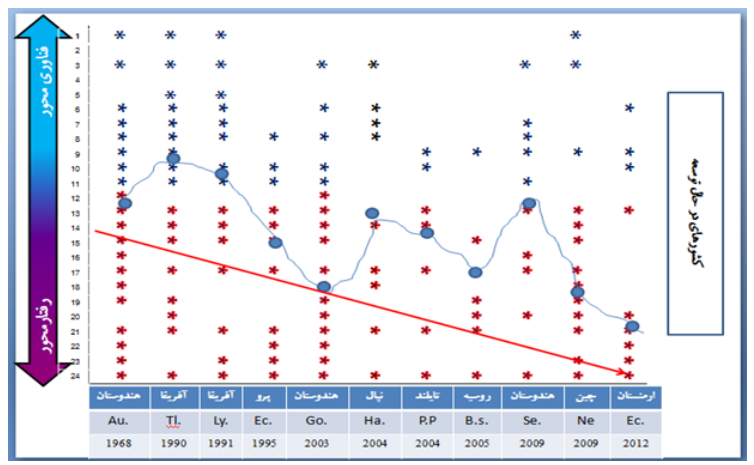

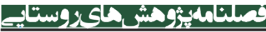

تصوير ب.الكوى زيستبومهاى بايدار كشورهاى در حالتوسعه (مثبع: يافتههاي

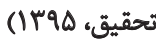

2. Plus Energy

درحال توسعه و توسعهيافته را شناسايى و طراحى كردند. الكوها/

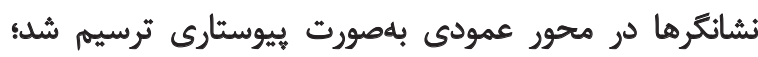

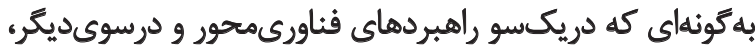

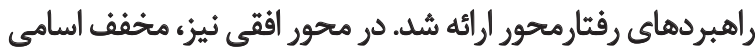

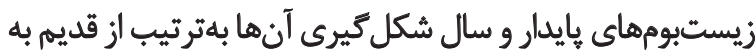
جديد و كشورهاى مرتبط درج شد (تصاوير شماره او (Y).

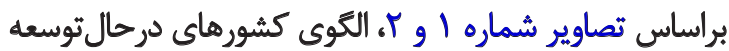

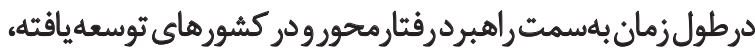

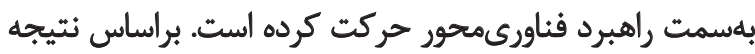
تحليل محتوا در تصوير شماره ا، كشور آلمان در بين كشوردهاي براي نتيج

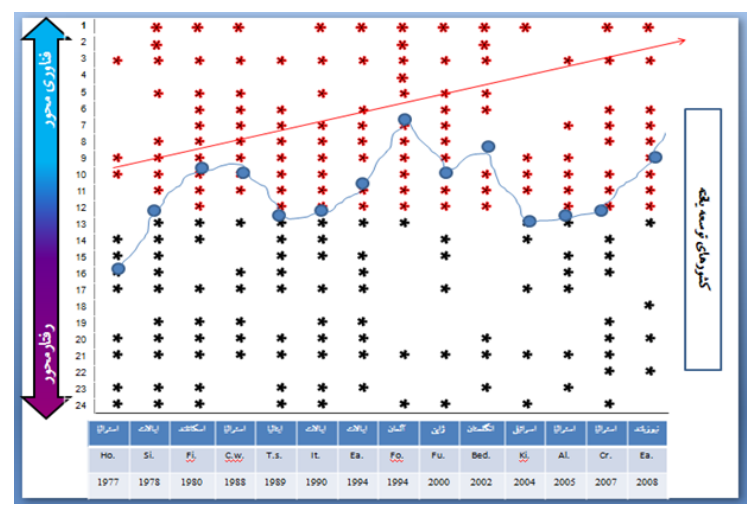

\section{مسلمبن}

تصوير اه التوى زيستبومهاي بايدار كشورهاي توسعهيافته (مئب: يافتههاى

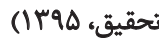




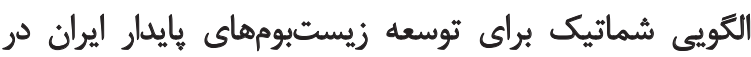

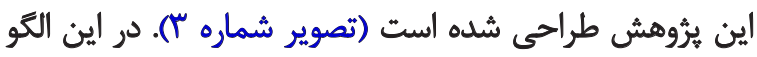

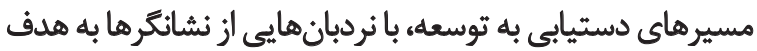

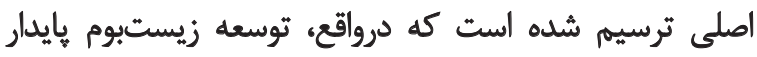

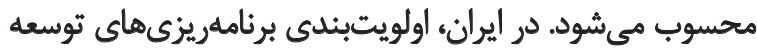

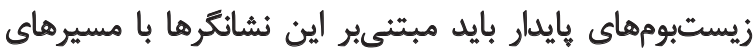

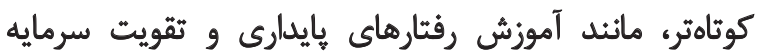

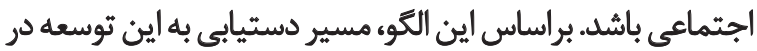

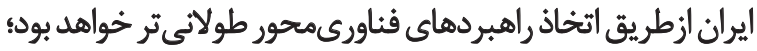

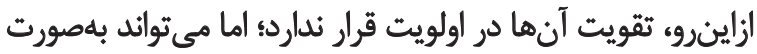

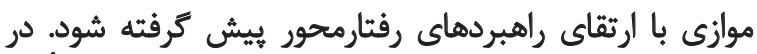

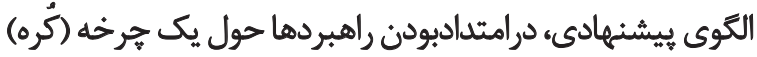

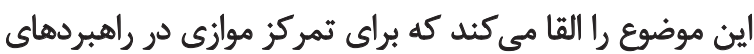

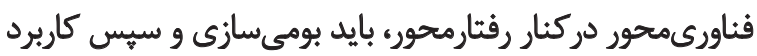
آنها بيش ترفته شود (تصوير شماره "َ).

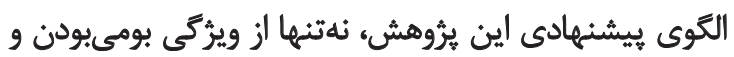

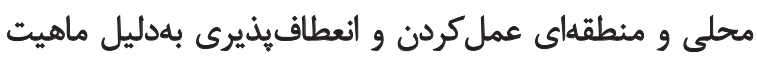

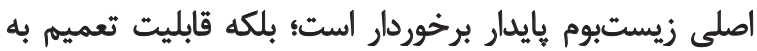

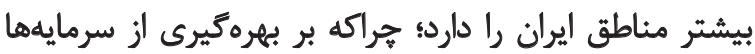

1، قراركيرى زيستبومهاى بايدار استراليا عموماً در حدمتوسط

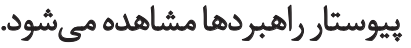

در بين كشورهاى درحال توسعه، هندوستان در حوزه فناورى در جايكًاه سوم جهان قرار دارد (Analytical Agency of Iran, 2014)

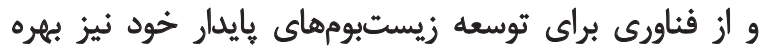

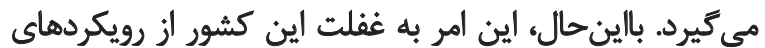

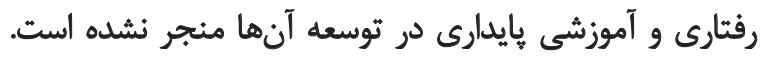

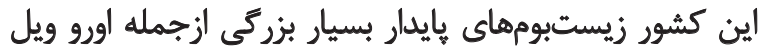

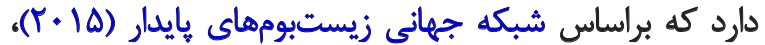

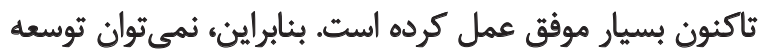

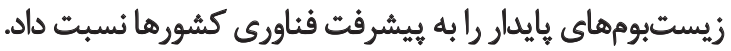
در آفريقاى جنوبى روند مذكور با كمى انحراف مواجه بوده و ورئوري

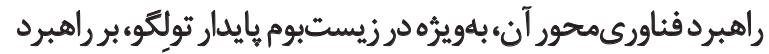

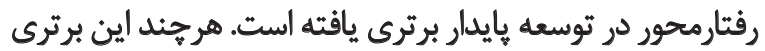

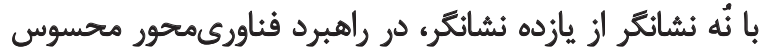

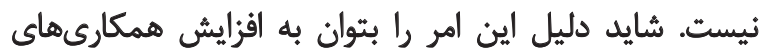
اتحاديه ارويا با آفريقاى دجنوبي نسبت داد اد (Masters, 2014). باتوجلبه نتايج تحليل محتواى كفتلشده و مقايسه اخير،

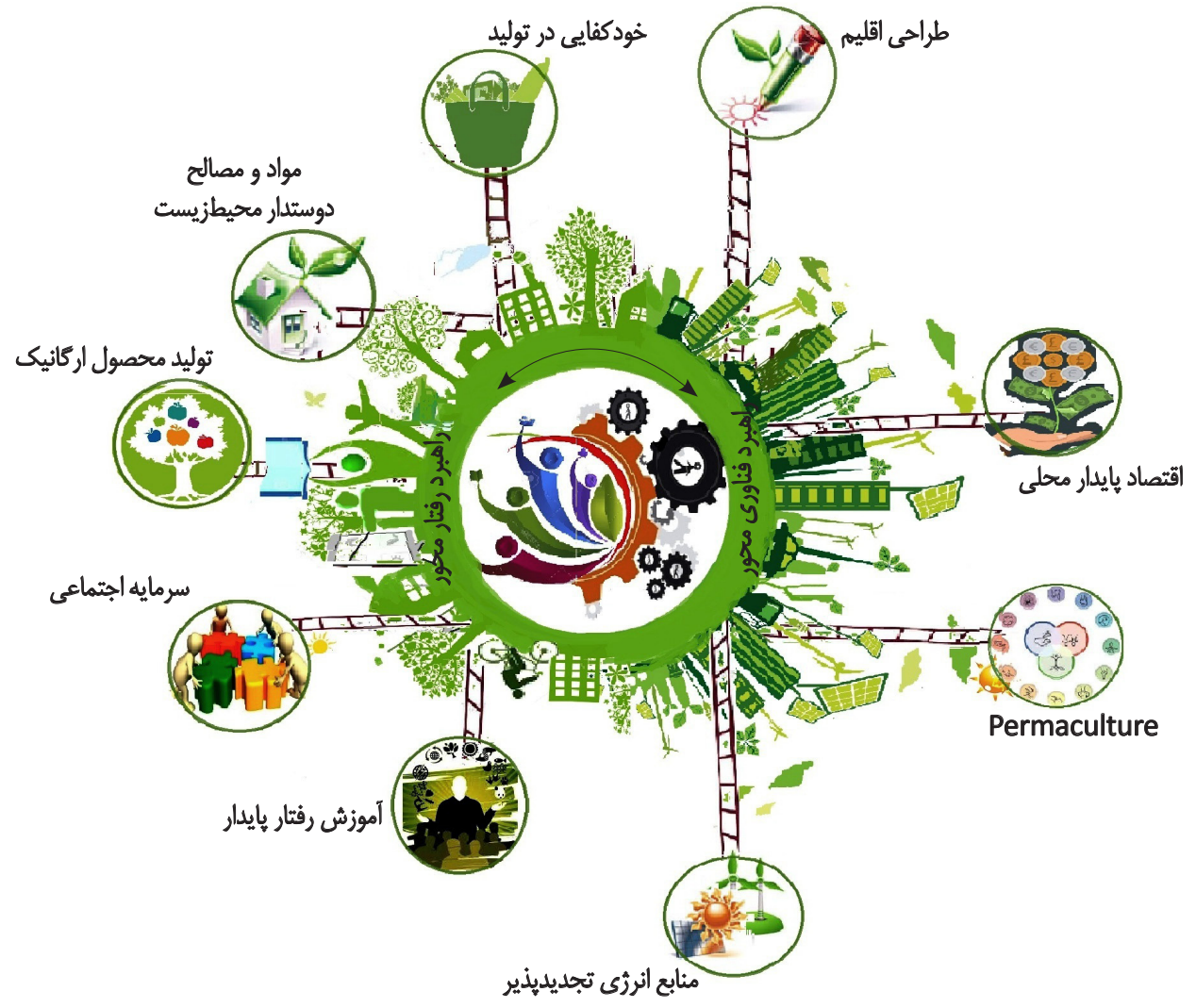


باوجوداين، از ثروتهاي عظيم انسانى و دانش بومى برخوردار است

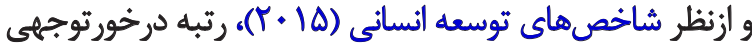

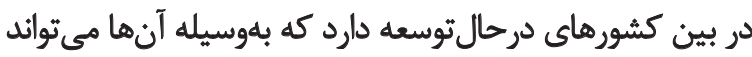
به دستاوردهاى باشكوهى برسد (Hamzei \& Fazelbeygi, 2011b). براين|ساس، نخستين كَام ايران در زمينه ايجاد الكوهاى

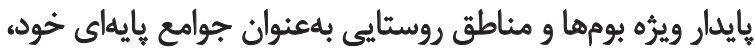

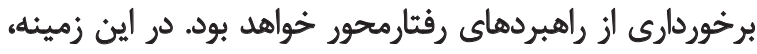

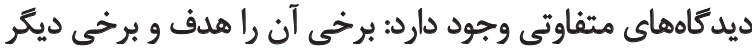

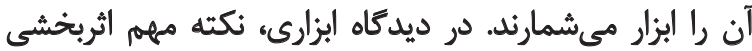

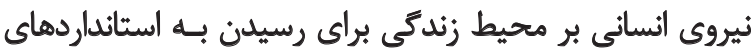

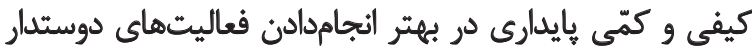

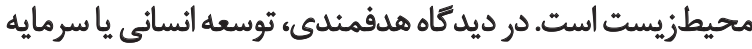

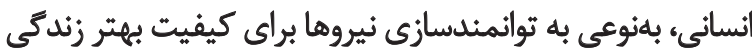

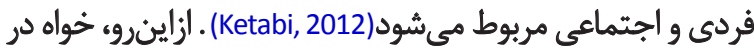

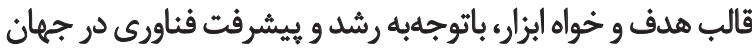

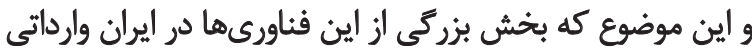

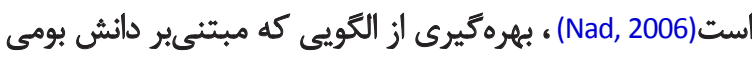

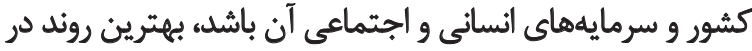

مسير توسعه زيستبومهاى يايدار اين مرزوبوم خواهد بوانود.

براساس الكوى بيشنهادى، آموزش رفتارهاى بايداري مهمهترين

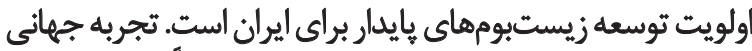

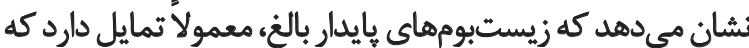

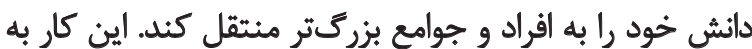

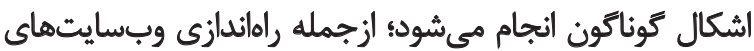

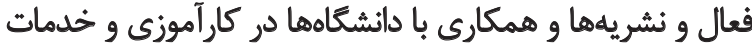

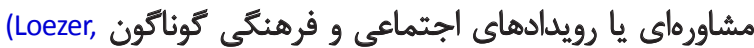
اين فرصتهاى 2011; Cohen, 2010; Irrgang, 2005; Giani, 2011). آموزشى، موجب برقرارى ارتباط بين زيستبومهاى غإيدار

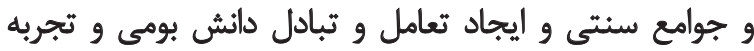

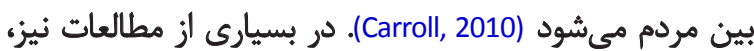

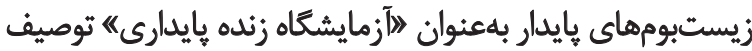

(Zamchevska, 2013; Loezer, 2011; Cohen, 2010). شده است نانس

موضوع مهم ديخر در الكوى بيشنهادى، ثقويت سرمايههاى

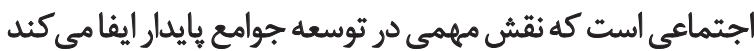
؛(Williams, 2005; Newman \& Dale, 2005; Lehtonen, 2004) يعنى بدون وجود ارزشهاي اجتماعى و فردى، از خشهماندازها

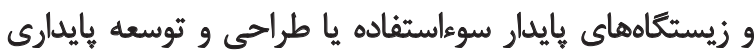

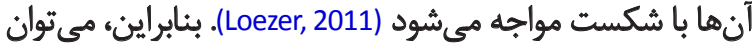

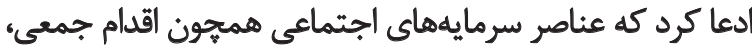

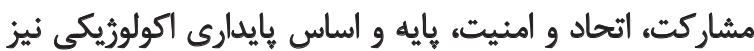

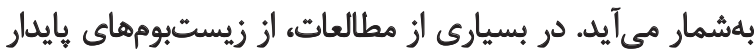

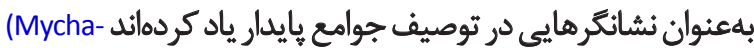
جوامع روستايى ايران نيز نسلهاست
و فناورىهاى سازكار با محل، در يهيوند با الكَوهاي اجتماعى و رفتارى و فرهنتى بومى تأكيد دارد.

\section{بحث و نتيجه}

در يُروهش حاضر، التوهاى توسعه زيستبومهاى ثايدار در

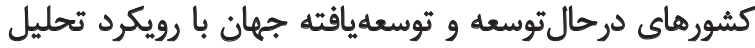

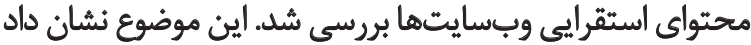

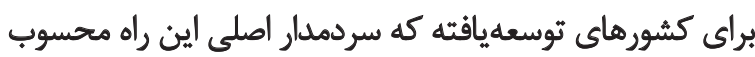

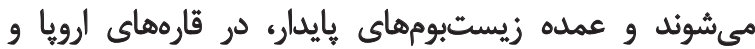

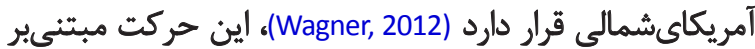

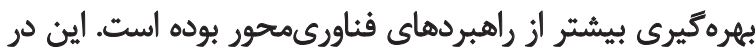

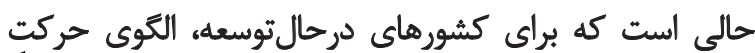

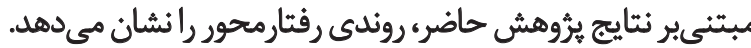

در توضيح بايد اشاره كرد كه برخى از انديشمندان و مسئولان

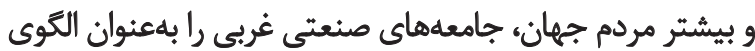

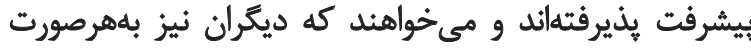

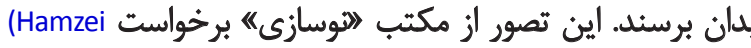
\& Fazelbeygi, 2011a)

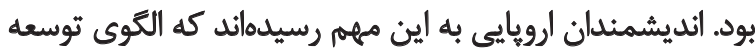

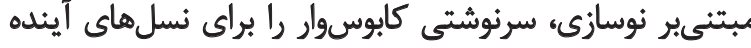

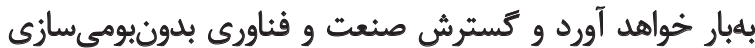

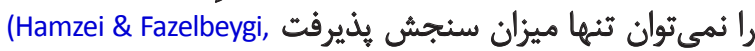

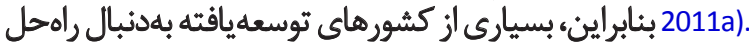

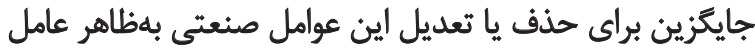

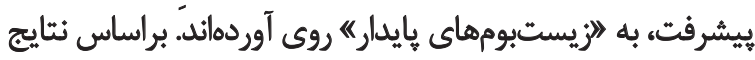

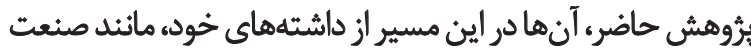

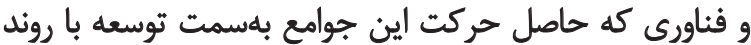

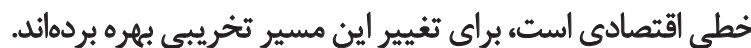

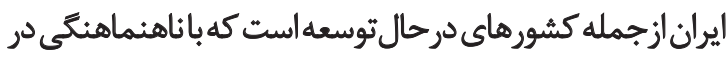

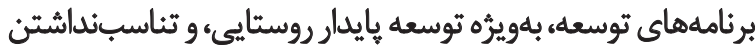

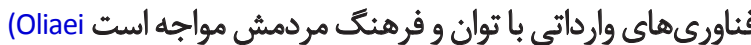

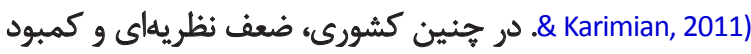

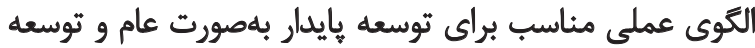

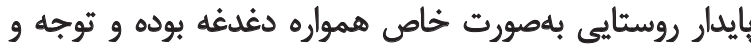

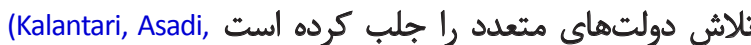
ShabanaliFami, \& Chubchyan, 2007)

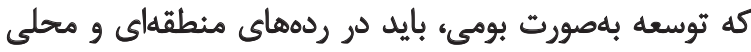

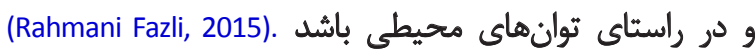

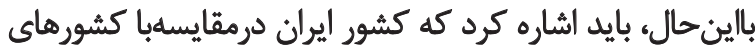

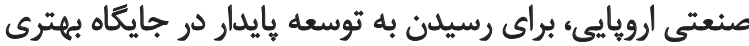

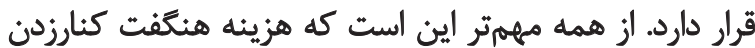

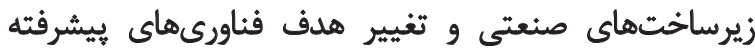
صنعتى خود به فناورىهاى سبز و دوستدار محيطزيست راندارئ فنارد. 
اين فناورىها، به تحقيقات زمينهيابى و بومى سازى با فرهنك و ورئي شرايط اقليمى و معيشتى روستاهاى ايران نياز دارد.

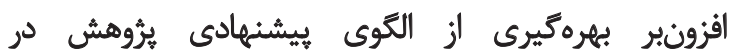

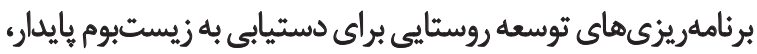

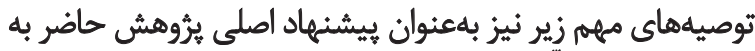

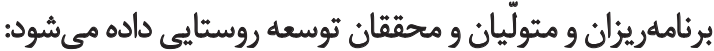
ا. انجام تحقيقات وسيع و عميق در مناطق روستايى ايران

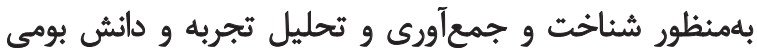

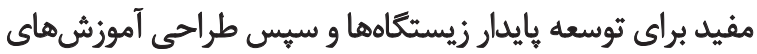

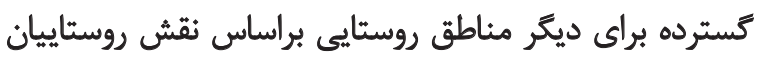

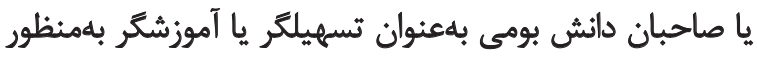

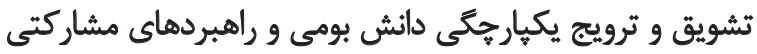

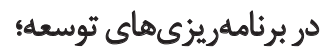

r. توسعه و بازسازى و نوسازى سكونتكاههاى روستايي،

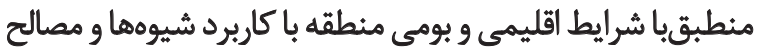

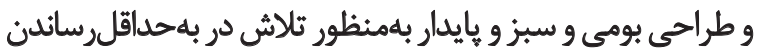

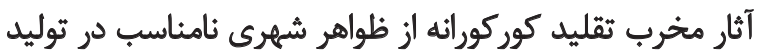

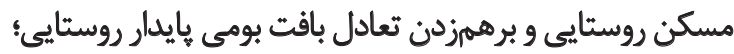

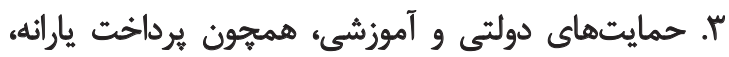

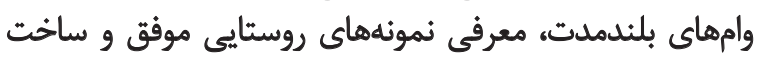

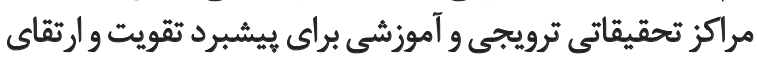

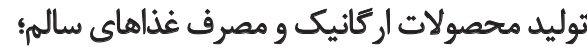

Fثا. تنوعبخشى فعاليتهاي اقتصادى روستايى افزونبر فعاليتهاي

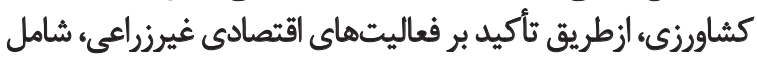

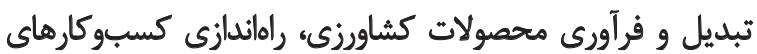

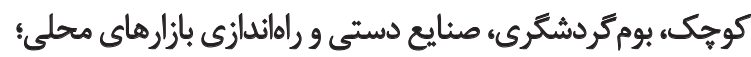

ه. بررسى توانهاي منطقهاى، جستوجو، تطبيق و بوميى سازيى

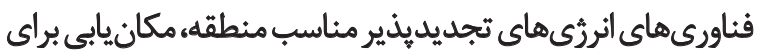

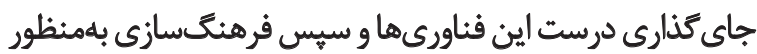
بهرهبردارى درست از آنهاري

$$
\text { تشكر وقدردانى }
$$

اين مقاله از ياياننامه مقطع كارشناسى ارشد خانم شهرزاد بارانى

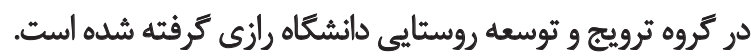

كه كنجيئه بالرزشى از جئين سرمايههايى را با خود حفظ و در در عصر حاضر، ارزش تقويت را بيشازيش إزيش درك مى كند. از ديكر رويكردهاى زيستبومهاى بايدار كه براى ايران نيز

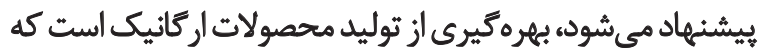

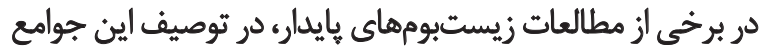

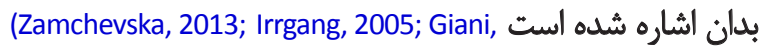

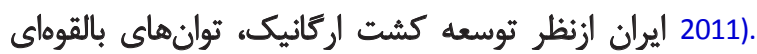

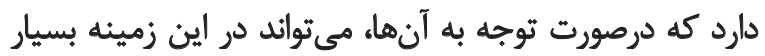

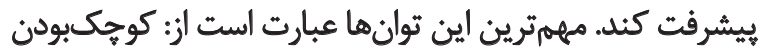

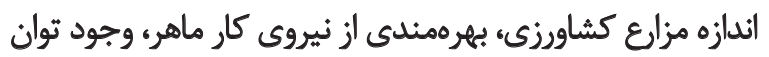

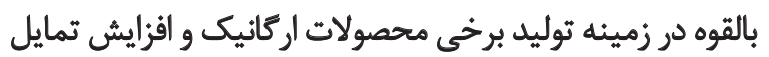
مصرفكنيدكان به استفاده از محصولات ساله(Abdullahi, 2008). طرحبندى، منظرهسازى، مكان كذارى و طراحى كلى روستاهاى

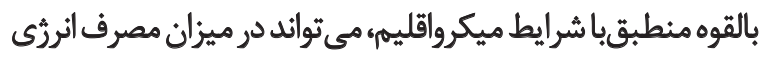

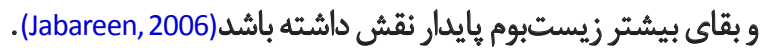

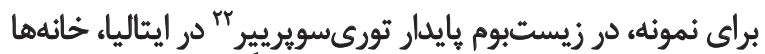

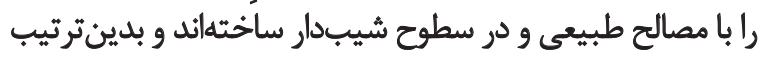

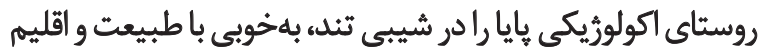

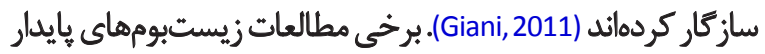

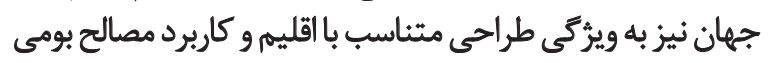

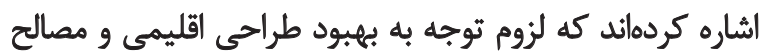

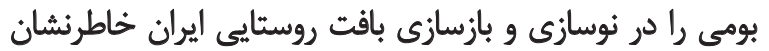

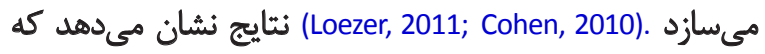

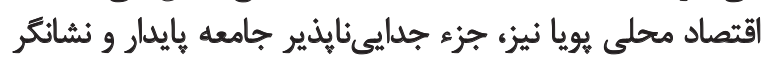

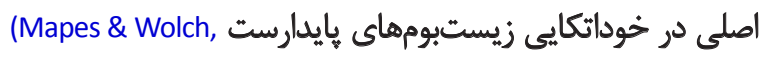

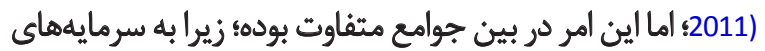
دردسترس وابسته است(Princr, 2010).

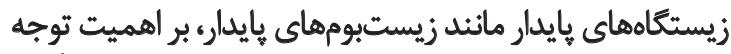

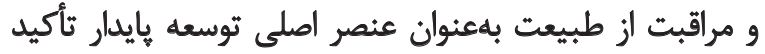

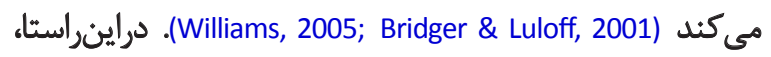

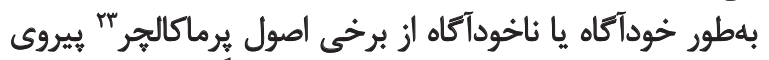

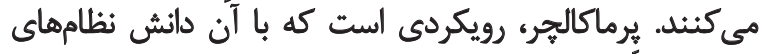

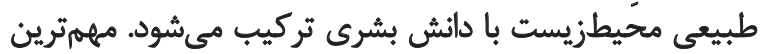

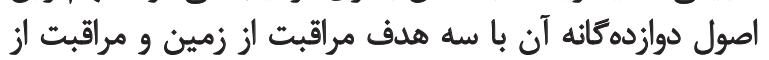

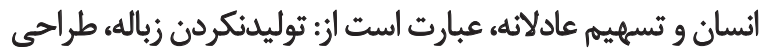
الكوها با جزئيات، استفاده خلاقانه و ياسخ به تغيير (Irrgang, 2005).

در طراحى و توسعه جوامع يايدار، بايد مبحث انررئ را نيز

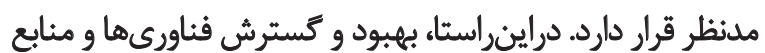

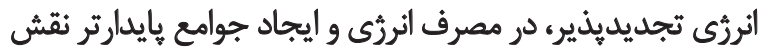

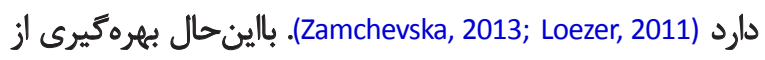

22. Torri Superiore

23. Permaculture 


\section{References}

Abdullahi, S. (2008). [Estimation of prospects of development of organic farming in Iran (Persian)]. Tehran: Ministry of Agriculture

Analytical Agency of Iran. (2014). [Why Japan is the world's technology leaders? / Germany, China, India and America and Korea, where are they? (Persian)] [Internet]. Retrieved from http://www.khabaronline.ir

Bridger, J. C., \& Luloff, A. E. (2001). Building the sustainable community: Is social capital the answer? Sociological Inquiry, 71(4), 458-472. doi: 10.1111/j.1475-682x.2001.tb01127.x

Carroll, E. (2010). Twenty-five years in the making: Why sustainable development has eluded the UN, and how community-driven development offers the solution. Houston Journal of International Law, 32(2), 546-585.

Cohen, P. A. (2010). Design for sustainable communities: An integral perspective [MA thesis]. Stellenbosch: University of Stellenbosch.

Dach, L., \& Allmendinger, K. (2014). Sustainability in corporate communications and its influence on consumer awareness and perceptions: A study of H\&M and primark. Procedia-Social and Behavioral Sciences, 130, 409-418. doi: 10.1016/j.sbspro.2014.04.048

Fischetti, D. M. (2008). Building resistance from home ecovillage at Ithaca as a model of sustainable living [MSc. Thesis]. Eugene: University of Oregon.

Firouzbakht, A., Parhizgar, A., \& Rabifar, V. (2012). [Strategies of environmental structure city with approach urban sustainable development (Case study: city of Karaj) (Persian)]. Human Geography Research Quarterly, 80, 213-239.

Giani, A. (2011). Novelties, retro-innovation and fantasy: Torri superiore ecovillage as a form of resistance to the abandonment of rural marginal areas in Italy [MSc. thesis]. Wageningen: Wageningen University.

Global Ecovillage Network (GEN). (2015). World map [Internet]. Retrieved from http:/ / www.gen.ecovillage.org

Hamzei, M. R., \& Fazelbeygi, M. (2011a). [From underdevelopment to sustainable development (Volume 1) (Persian)]. Kermanshah: University of Razi Pub.

Hamzei, M. R., \& Fazelbeygi, M. (2011b). [Global theories of development and underdevelopment, (Volume 2): global theories of sustainable development (Persian)]. Kermanshah: University of Razi Pub.

International Monetary Fund (IMF). (2016). World economic outlook: Too slow for too Long. Washington: International Monetary Fund.

International Monetary Fund (IMF). (2015). World economic outlook: too slow for too long. Washington: International Monetary Fund.

Irrgang, B. (2005). A study of the efficiency and potential of the ecovillage as an alternative urban model [MSc. thesis]. Stellenbosch: University of Stellenbosch.

Jabareen, Y. R. (2006). Sustainable urban forms: Their typologies, models, and concepts. Journal of Planning Education and Research, 26(1), 38-52. doi: $10.1177 / 0739456 \times 05285119$

Ketabi, A. (2012). [Effective role of human capital in the Iranian capital (Persian)]. Mashhad: Department of Planning, Modernization and Administrative Change.
Kirby, A. (2003). Redefining social and environmental relations at the ecovillage at Ithaca: A case study. Journal of Environmental Psychology, 23(3), 323-332. doi: 10.1016/s0272-4944(03)00025-2

Lehtonen, M. (2004). The environmental-social interface of sustainable development: Capabilities, social capital, institutions. Ecological Economics, 49(2), 199-214. doi: 10.1016/j.ecolecon.2004.03.019

Lin, S. L. (2007). Pattern language of ecovillage design: A research focusing on patterns in three ecovillages in Sweden [MSc. thesis]. Stockholm Royal Institute of Technology.

Loezer, B. L. (2011). Enhancing sustainability at the community level: lessons from American ecovillages [MSc. thesis]. Cincinnati: University of Cincinnati.

Mapes, J., \& Wolch, J. (2011). “Living green": The promise and pitfalls of new sustainable communities. Journal of Urban Design 16(1), 105-126. doi: 10.1080/13574809.2011.521012

Masters, L. (2014). The EU and South Africa: Towards a new partnership for development, policy brief 11. Madrid: FRIDE: A European think tank global action.

Miller, E., \& Bentley, K. (2012). Leading a sustainable lifestyle in a 'non-sustainable world': Reflections from Australian ecovillage and suburban residents. Journal of Education for Sustainable Development, 6(1), 137-147. doi: 10.1177/097340821100600120

Mychajluk, L. H. (2014). Building capacity to live and work together at an ecovillage in support of sustainable community [MSc. thesis]. Toronto University of Toronto

Nad, R. (2006). [Technology development and its environmental impacts (Persian)]. Quarterly Journal of Industrial Technology Development, 4(10), 36-44

Newman, L., \& Dale, A. (2005). The role of agency in sustainable local community development. Local Environment, 10(5), 477-486. doi: 10.1080/13549830500203121

Nippala, J. J. (2013). Corporate social responsibility in north Carolina's small and medium-sized forest products companies [MSc. thesis]. Helsinki: Helsinki University.

Oliaei, M. S., \& Karimian, H. (2011). [Investigating the rural development approach in Iran with an emphasis on the role and position of local knowledge (Persian)]. Journal of Iranian Social Development Studies, 3(3), 85-101.

Prince, M. N. (2010). Investigating the livelihoods of families operating small sugarcane farms in Jamaica [PhD. thesis]. Lincoln: Lincoln University.

Rahmani Fazli, A. R. (2015). [The model of Balanced regional Sustainable development (Persian)], Tavazon Journal, 2(25), 1.

Sandelowski, M., Docherty, S., \& Emden, C. (1997). Qualitative metasynthesis: Issues and techniques. Research in Nursing $\mathcal{E}$ Health 20(4), 365-371. doi: 10.1002/(sici)1098-240x(199708)20:4<365::aidnur9>3.3.co;2-7

Schilling, J. (2006). On the pragmatics of qualitative assessment European Journal of Psychological Assessment, 22(1), 28-37. doi 10.1027/1015-5759.22.1.28

Suri, H. (1999). The process of synthesising qualitative research: A case study. Paper presented at The Annual Conference of the Association for Qualitative Research, Melbourne, Australia, 7 July 1999. 
Tabrizi, M. (2014). [A qualitative content analysis from the point of view of comparative and inductive approaches (Persian)]. Journal of Social Sciences, 64, 105-138.

Tinsley S., \& George, H. (2006). Ecological footprint of the findhorn foundation and community. Forres: HIE Moray.

Trainer, T. (1995). The conserver society: Alternatives for sustainability. London: Zed Books.

United Nations Development Programme. (2015). Human Development Report (HDR) 2015. Work for human development. New York: United Nations Development Programme.

Veteto, J. R., \& Lockyer, J. (2008). Environmental anthropology engaging permaculture: Moving theory and practice toward sustainability. Culture $\mathcal{E}$ Agriculture, 30(1-2), 47-58. doi: 10.1111/j.1556-486x.2008.00007.x

Wagner, F. (2012). Ecovillage research review. In A. Marcus, and F. Wagner (Eds.), Realizing Utopia: Ecovillage Endeavors and Academic Approache (pp. 81-94). Munich: Rachel Carson Center.

Waerther, S. (2014). Sustainability in ecovillages - A reconceptualization. International Journal of Management and Applied Research, 1(1), 1-16. doi: 10.18646/2056.11.14-001

Williams, J. (2005). Designing neighbourhoods for social interaction: The case of cohousing. Journal of Urban Design, 10(2), 195-227. doi: 10.1080/13574800500086998

Wu, Y. J., Huang, S., Kuo, L., \& Wu, W. (2010). Management education for sustainability: A web-based content analysis. Academy of Management Learning \& Education, 9(3), 520-531. doi: 10.5465/ amle.2010.53791832

Weed, M. (2005). Meta interpretation: A method for the interpretive synthesis of qualitative research. Forum: Qualitative Social Research, $6(1), 37$.

World Bank (2015). Country and lending groups [Internet]. Retrieved from http://Www.worldbank.org

Xhexhi, A. K. (2011). From ecovillages to Tirana [MSc. thesis]. Albania: Epoka University.

Yin, R. (1989). Case study research, design and methods. California: Sage Pub.

Zamchevska, I. (2013). Sustainable development principals in a community setting [MSc. thesis]. Saskatoon: University of Saskatchewan.

Zeighami, R., Bagheri Nesami, M., Haghdoost Oskouie, S. F., \& Yadavar Nikravesh, M. (2008). [Content analysis (Persian)]. Iran Journal of Nursing, 21(53), 41-52. 